\title{
THE EFFECT OF FLUID FROM THE CAUDA EPIDIDYMIDIS, SERUM COMPONENTS AND CAFFEINE UPON THE SURVIVAL OF DILUTED EPIDIDYMAL HAMSTER SPERMATOZOA
}

\author{
B. MORTON AND T. S. K. GHANG \\ Department of Biochemistry and Biophysics, University of Hawaii, \\ Honolulu, Hawaii 96822, U.S.A:
}

(Received 10th October 1972)

\begin{abstract}
Summary. When epididymal hamster spermatozoa were diluted in increasing amounts of Tyrode's solution, their survival diminished markedly. If, instead, they were diluted in $20 \%$ 'cauda epididymidis' fluid (CEF), their survival increased. The active factor of CEF was found to be of low molecular weight and heat stable. If the spermatozoa were diluted in the presence of caffeine or a capacitating medium derived from human serum, their survival was not significantly increased but the rate of those moving was markedly stimulated. Human serum components, but not caffeine-albumin or epididymal fluid-albumin, capacitated hamster spermatozoa. The survival-promoting factor of epididymal fluid did not appear to act through sperm cyclic AMP metabolism.
\end{abstract}

\section{INTRODUCTION}

More than a century ago, it was observed that dilution of semen in vitro caused a rapid decline in the viability of the spermatozoa contained therein (Koelliker, 1856). Much effort has been devoted to the understanding of this phenomenon and to the design of diluents to enhance sperm survival. Although at least fifteen different proposals have been put forward (Mann, 1964), the biochemical basis of this dilution effect remains unclear. The introduction of an 'eggyolk-phosphate diluent' by Phillips \& Lardy (1940) made it possible to preserve dilute semen for longer periods.

While investigating the biochemistry of hamster sperm capacitation, we found that these spermatozoa would not survive the required 4-hr incubation period if they were diluted 100 -fold in Tyrode's solution. If the spermatozoa were only diluted tenfold, however, their motility was of a higher quality and similar to that reported by Morita \& Chang (1970). Here we report investigations on some factors that modify the survival of diluted epididymal hamster spermatozoa.

\section{MATERIALS AND METHODS}

Spermatozoa in 'cauda epididymidis' fluid (CEF) was obtained by passing a No. 22 disposable syringe needle ten times through the caudal portions of 
saline-washed epididymides removed from 60- to 90-day-old golden hamsters. About $0.5 \mathrm{ml}$ sperm-containing fluid was extruded into a small Petri dish containing $2 \mathrm{ml}$ Tyrode's solution at room temperature by pressing the epididymis with a haemostat. The spermatozoa were dispersed by 5 min incubation at $37^{\circ} \mathrm{C}$ and transferred to a stoppered $15-\mathrm{ml}$ centrifuge tube.

Because the epididymal exudate was diluted fivefold, the concentration of the CEF present in the supernatant fraction of this sperm suspension was arbitrarily assigned a value of $20 \%$. Due to variation in size and content of the epididymides, the concentration of the fluid may occasionally have been as low as $10 \%$. Because Tyrode's solution has been found to be compatible with hamster spermatozoa (Morita \& Chang, 1970), it was used as a diluent unless stated otherwise.

Sperm concentrations were determined using a haemocytometer. Motility was rated both in terms of percentage of spermatozoa moving and rate on an arbitrary scale of 0 to 10 . The precision of motility evaluation by the personnel in our laboratory is quite high due to a mutually agreed rating code and regular rating comparisons.

To obtain $20 \%$ epididymal fluid for use as a diluent, the above sperm suspension was centrifuged at $1000 \mathrm{~g}$ for $5 \mathrm{~min}$ at room temperature and the pellet was discarded. When necessary, spermatozoa were washed by centrifugation at room temperature for $2 \mathrm{~min}$ at $500 \mathrm{~g}$ and resuspended in the desired medium by gentle swirling.

Human serum was obtained by collecting blood samples without anticoagulants and heating at $56^{\circ} \mathrm{C}$ for $30 \mathrm{~min}$. After the sample was passed through a millipore filter of $0.3-\mu \mathrm{m}$ pore size, the $\mathrm{pH}$ was adjusted to $7 \cdot 6$ and the sample was frozen. Serum dialysate was prepared from this by dialysing at $4^{\circ} \mathrm{C}$ against an equal volume of Tyrode's solution for $18 \mathrm{hr}$.

The technology of hamster sperm capacitation and assay is presented elsewhere (Morton, Rogers \& Chang, 1973).

As a standard, we used $4 \times$ crystallized human serum albumin from Nutritional Biochemicals Corp., Cleveland, Ohio.

\section{RESULTS}

The deleterious effect of dilution upon the survival of epididymal hamster spermatozoa is illustrated in Text-fig. 1. Motility diminished with dilution both in terms of percentages of spermatozoa moving and rate.

Quite a different result occurred when the spermatozoa were diluted with $20 \%$ CEF. This is shown in Text-fig. 2 where it may be seen that the more the spermatozoa were diluted, the more viable they became. In all cases, motility was extremely strong over at least the first $4 \mathrm{hr}$.

Text-figure 3 shows that, at a constant sperm concentration, sperm survival was directly related to the concentration of epididymal fluid present in the incubation media.

The variability of our data is shown in Table 1 where it may be seen that the survival of spermatozoa in $20 \% \mathrm{CEF}$ is significantly greater than in $1 \% \mathrm{CEF}$. Table 1 also shows that the component in epididymal fluid that is responsible 
for this survival is stable to $100^{\circ} \mathrm{C}$ for at least $10 \mathrm{~min}$, and is able to penetrate dialysis membranes.

Yanagimachi (1970) has reported that the rate of motility of epididymal hamster spermatozoa is elevated by components of human serum which bring about sperm capacitation. This led us to test the effect of serum upon the survival of the much larger numbers of hamster spermatozoa used in our experiments. The result of several of these experiments is depicted in Text-fig. 4.

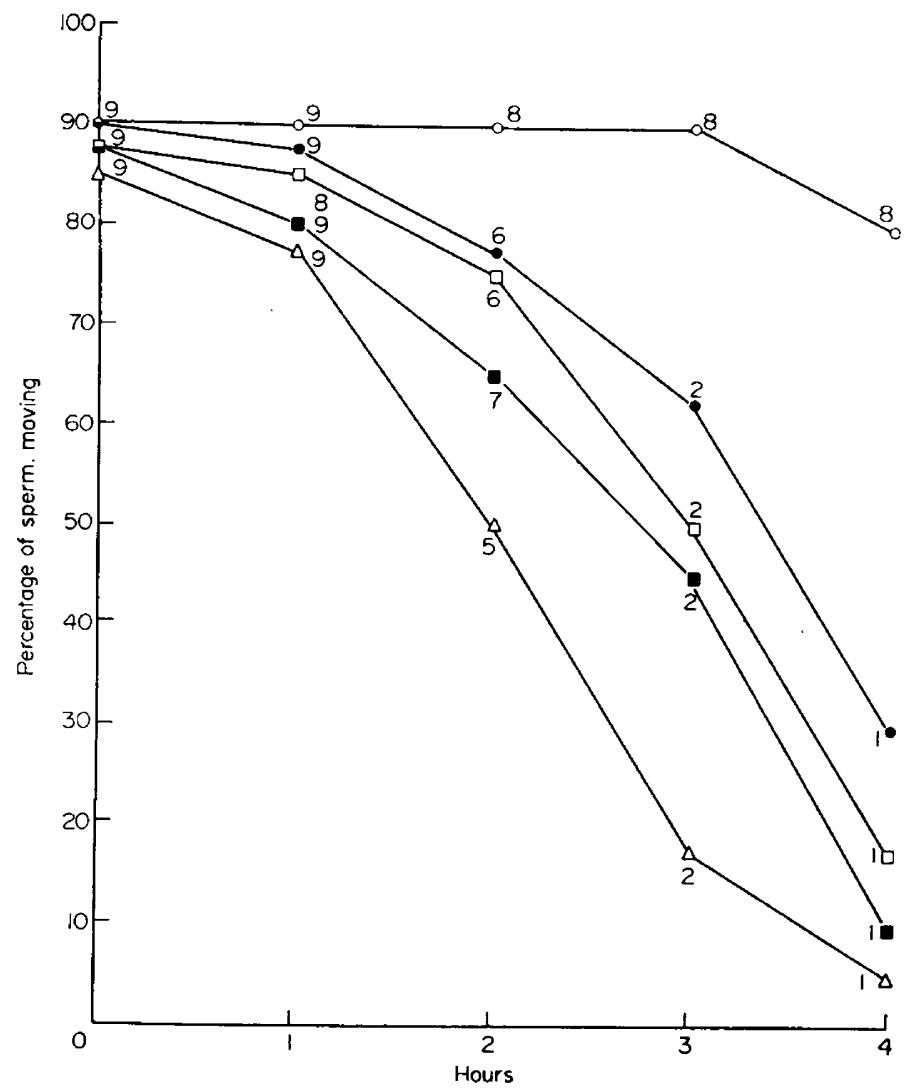

TExT-FIG. 1. The effect on motility of diluting both hamster spermatozoa and epididymal fluid equally. Samples containing $10^{8}$ spermatozoa $/ \mathrm{ml} \mathrm{20 \%}$ 'cauda epididymidis' fluid (CEF) were diluted in increasing amounts of Tyrode's solution. $0,10 \times 10^{7}$ spermatozoa/ $\mathrm{ml}$ of $20 \% \mathrm{CEF} ; \bullet, 5 \times 10^{7}$ spermatozoa $/ \mathrm{ml}$ of $10 \%$ CEF; $\square, 2.5 \times 10^{7}$ spermatozoa $/ \mathrm{ml}$ of $5 \%$ CEF; $\boldsymbol{\square}, 1.0 \times 10^{7}$ spermatozoa $/ \mathrm{ml}$ of $2 \%$ CEF; $\triangle, 0.5 \times 10^{7}$ spermatozoa $/ \mathrm{ml}$ of $1 \%$ CEF. Numbers beside the data points refer to rate of motility on a scale of 0 to 10 .

Over the first $2 \mathrm{hr}$, the rate of motility of the spermatozoa in heat-detoxified serum dropped along with that of spermatozoa incubated in Tyrode's solution only. Over the last $2 \mathrm{hr}$, however, there was a substantial increase in rate of motility of spermatozoa incubated in the presence of serum. Spermatozoa incubated in the presence of serum dialysate plus human albumin retained a high rate of motility throughout the incubation period.

In terms of sperm survival, an important difference was observed between 
the effect of CEF and that of serum components. As shown in Text-fig. 4, the percentage of spermatozoa moving at $4 \mathrm{hr}$ in the presence of serum components was only 5 to $15 \%$ above that in Tyrode's solution alone. Yet, in Text-fig. 3, it may be seen that elevations in epididymal fluid above the $5 \%$ present in the serum experiments of Text-fig. 4 cause a striking preservation of the percentage of spermatozoa moving at $4 \mathrm{hr}$.

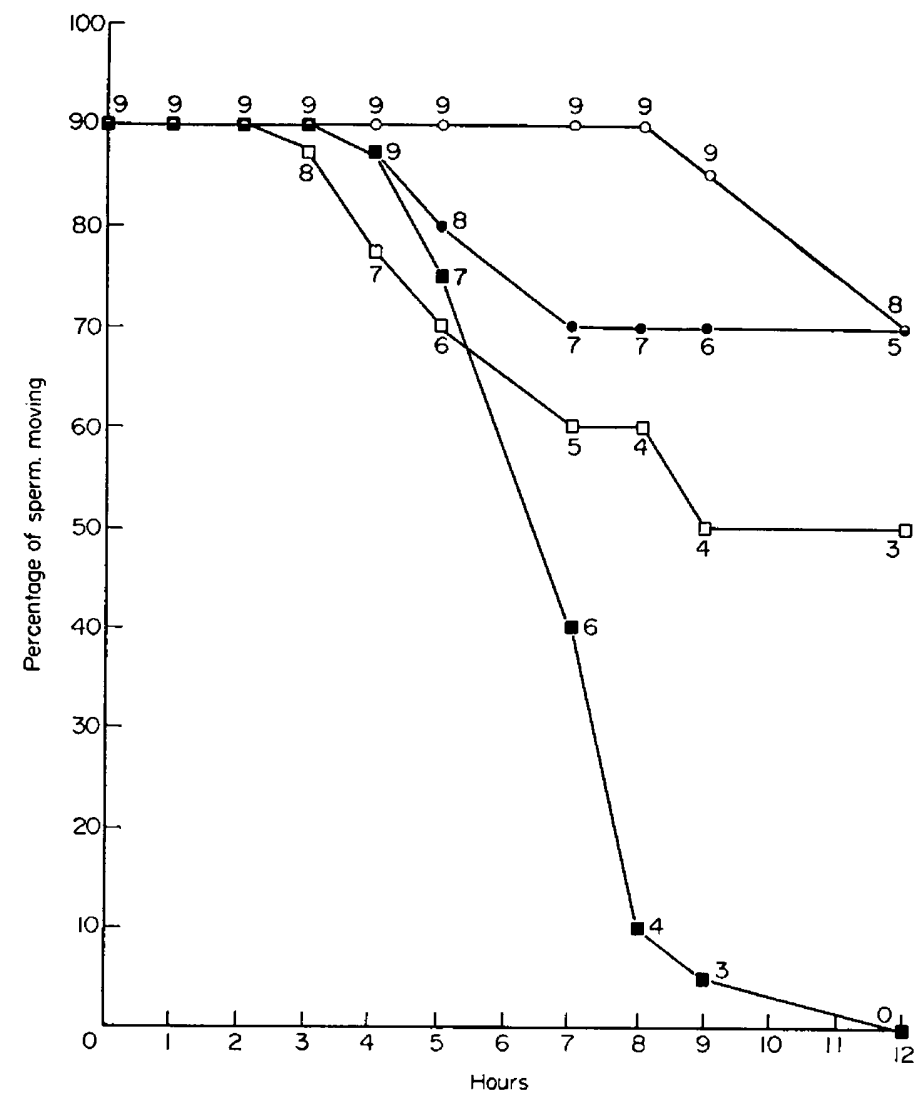

Text-FIc. 2. The effect of dilution of hamster spermatozoa, but not epididymal fluid, upon motility. Samples containing $10^{8}$ spermatozoa $/ \mathrm{ml}$ in $20 \%$ 'cauda epididymidis' fluid (CEF) were diluted in increasing amounts of $20 \% \mathrm{CEF}$. $\mathrm{m}, 5 \times 10^{7}$ spermatozoa $/ \mathrm{ml}$ of $20 \% \mathrm{CEF}$; $\square, 2.5 \times 10^{7}$ spermatozoa $/ \mathrm{ml}$ of $20 \% \mathrm{CEF} ; 0,1.0 \times 10^{7}$ spermatozoa $/ \mathrm{ml}$ of $20 \% \mathrm{CEF} ; 0,0.5 \times 10^{7}$ spermatozoa $/ \mathrm{ml}$ of $20 \%$ CEF. Numbers beside data points refer to the rate of motility on a scale of 0 to 10 .

Using bull spermatozoa, Garbers, First, Sullivan \& Lardy (1971) and Garbers, Lust, First \& Lardy (1971) have reported that the cyclic AMP (cAMP) phosphodiesterase inhibitor, caffeine, stimulates both rate of motility and the percentage of spermatozoa moving. To determine if caffeine acts similarly to epididymal fluid in maintaining hamster sperm survival, the data shown in Text-fig. 5 were obtained. It may be seen that caffeine strongly elevated the rate of flagellation in a manner similar to serum dialysate. Unlike epididymal fluid, it did not prevent a rapid decrease in the percentage of spermatozoa mov- 


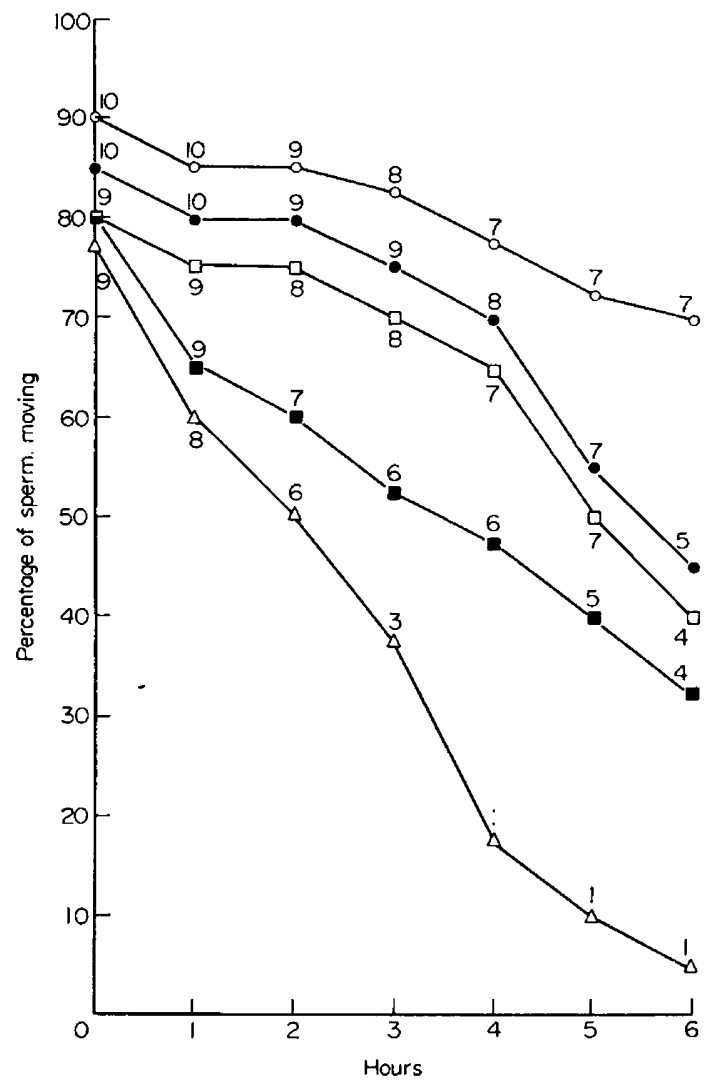

TEXT-FIG. 3. The effect of dilution of hamster epididymal fluid, but not spermatozoa, upon motility. Samples containing $2 \times 10^{7}$ spermatozoa $/ \mathrm{ml}$ were prepared by diluting spermatozoa in Tyrode's buffer containing increasing amounts of "cauda epididymidis fluid' (CEF). $\triangle, 2 \times 10^{7}$ spermatozoa $/ \mathrm{ml}$ of $1 \%$ CEF; $\mathbf{E}, 2 \times 10^{7}$ spermatozoa $/ \mathrm{ml}$ of $5 \%$ CEF; $\square, 2 \times 10^{7}$ spermatozoa $/ \mathrm{ml}$ of $10 \% \mathrm{CEF} ; \bullet, 2 \times 10^{7}$ spermatozoa $/ \mathrm{ml}$ of $15 \%$ CEF; $0,2 \times 10^{7}$ spermatozoa $/ \mathrm{ml}$ of $20 \% \mathrm{CEF}$.

Table 1. The effect on hamster sperm motility of whole, heated and dialysed epididymal fluid

\begin{tabular}{l|c|c}
\hline \multicolumn{1}{c|}{ Variable } & $\begin{array}{c}\% \text { sperm. } \\
\text { moving at } 4 \mathrm{hr}\end{array}$ & $\begin{array}{c}\text { No. of } \\
\text { experiments }\end{array}$ \\
\hline $1 \% \mathrm{CEF}$ & $11 \pm 5$ & 12 \\
$20 \% \mathrm{CEF}$ & $56 \pm 20$ & 17 \\
$20 \% \mathrm{CEF}, 100 \% \mathrm{C}, 10 \mathrm{~min}$ & $53 \pm 15$ & 5 \\
Dialysate of $20 \%$ CEF* & $30 \pm 18$ & 5 \\
Non-dialysable fraction of $20 \% \mathrm{CEF}$ & $5 \pm 4$ & 5 \\
Recombined dialysis fractions of $20 \% \mathrm{CEF}$ & $30 \pm 10$ & 5 \\
\hline
\end{tabular}

$\mathrm{CEF}=$ fluid from the canda epididymidis. Data are presented as the average \pm absolute range. The spermatozoa were centrifuged and resuspended to an averagc concentration of $2.5 \times 10^{7} / \mathrm{ml}$.

* Because dialysis was against an equal volume of Tyrode's solution, the final concentration of CEF was $10 \%$. 
ing in this system. Thus, at $4 \mathrm{hr}$, only $15 \%$ more of the spermatozoa were moving in the presence of $5 \mathrm{~mm}$-caffeine than in its absence.

A comparison was then made of the ability of epididymal fluid dialysate,

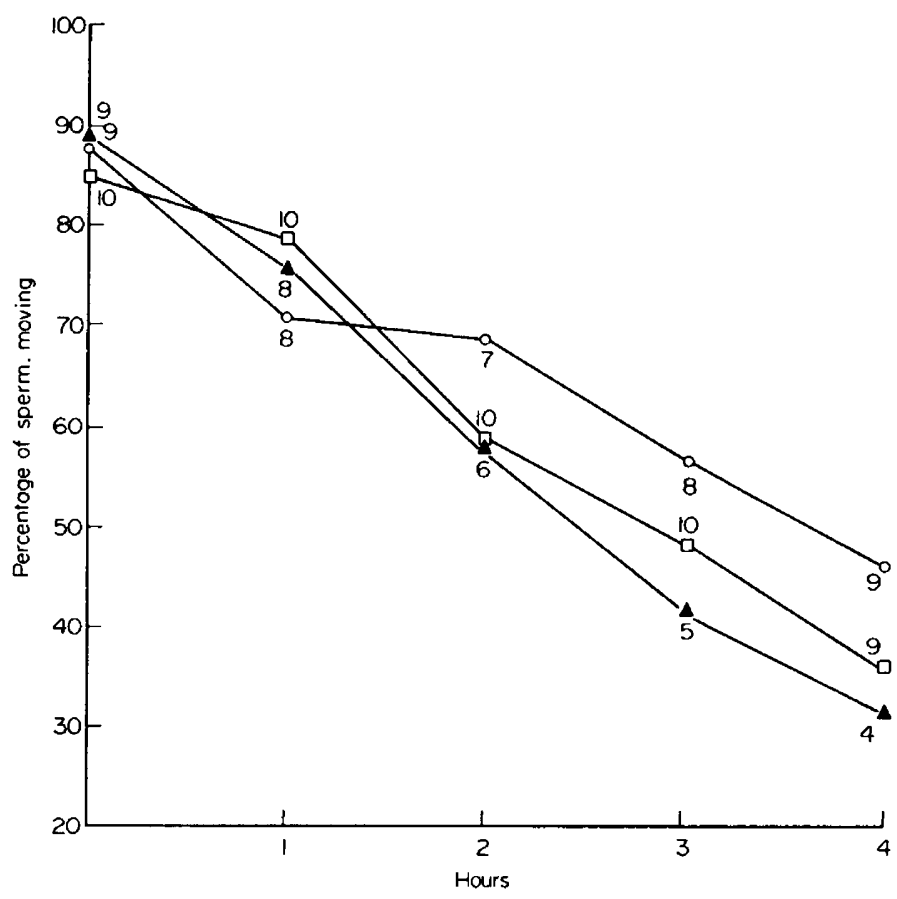

TExT-Fic. 4. The effect of serum components on the motility of epididymal hamster spermatozoa. All data are the average of the results of six experiments. Final sperm concentrations varied between 1 and $2 \times 10^{7} / \mathrm{ml}$. Spermatozoa $(0.5 \mathrm{ml})$ in Tyrode's buffer were diluted with an equal volume of: Tyrode's solution $(\Delta)$, heat-detoxified serum $(O)$ or serum dialysate containing $10 \mathrm{mg}$ crystalline human albumin ( $\square$ ). Numbers by the data points refer to rate of motility $(0$ to 10$)$.

Table 2. The ability of motility-promoting media to capacitate hamster spermatozoa in vitro

\begin{tabular}{l|c|c}
\hline \multicolumn{1}{c|}{ Incubation medium } & $\begin{array}{c}\text { No. of ova } \\
\text { fertilized/no. } \\
\text { of ova examined }\end{array}$ & $\begin{array}{c}\% \\
\text { fertilized } \dagger\end{array}$ \\
\hline $\begin{array}{c}\text { Scrum dialysate + albumin } \\
\text { 40\% CEF dialysate + }\end{array}$ & $28 / 42$ & 67 \\
albumin* & $0 / 29$ & 0 \\
10 mm Caffeinc + albumin & $0 / 28$ & 0 \\
\hline
\end{tabular}

CEF = fluid from the cauda epididymidis. Crystalline human albumin concentration was $10 \mathrm{mg} / \mathrm{ml}$.

* Because the CEF was dialysed against an equal volume of Tyrode's solution, it was equivalent in strength to $20 \%$ untreated CEF.

† Fertilization was judged to have occurred when swelling sperm heads still attached to flagella were observed within the vitellus. 
serum dialysate and caffeine to capacitate epididymal hamster spermatozoa in the presence of $10 \mathrm{mg} / \mathrm{ml}$ crystalline human albumin. To do this, the spermatozoa were incubated for $4 \mathrm{hr}$ and then added to hamster ova. Two hours after the gametes were combined, the ova were examined microscopically for sperm penetration. The results presented in Table 2 show that only serum dialysate plus albumin capacitated the spermatozoa.

Glycerylphosphorylcholine, a component found in epididymal fluid of the boar at levels as high as $30 \mathrm{mg} / \mathrm{ml}$ (Mann, 1964), was found to have no effect upon hamster sperm motility over the concentration range of 0.1 to $10 \mathrm{mg} / \mathrm{ml}$.

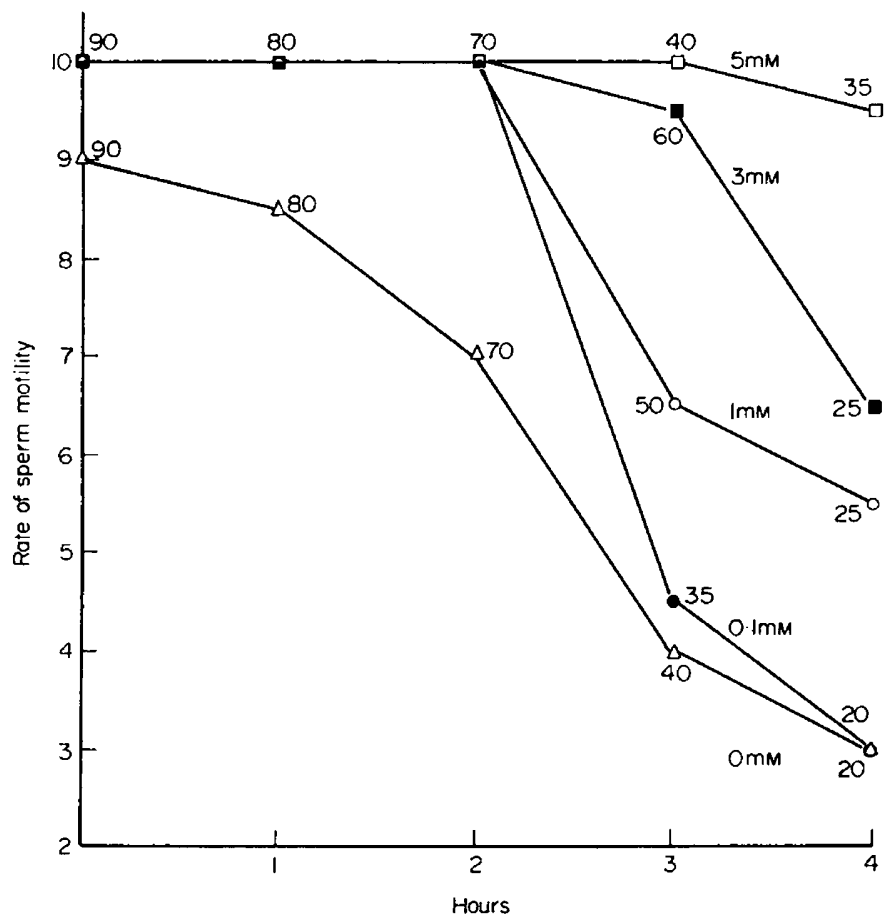

Text-FIG. 5. The effect of caffeine on the motility of epididymal hamster spermatozoa. Sperm concentration was $1.4 \times 10^{7} / \mathrm{ml}$ Tyrode's solution. Ciaffeine concentrations were as marked. Numbers by data points refer to percentage of spermatozoa moving.

\section{DISGUSSION}

When considering the great sperm dilution that occurs after insemination, our observation that sperm survival can be enhanced by dilution appears intuitively more acceptable than the opposite view, in spite of evidence accumulated over the last century against this. The reason for greater survival at high dilution may be related to the reduced output of toxic metabolic end products per unit volume or to a slower exhaustion of substrate.

The fact that the epididymal factor promoting sperm survival has a low molecular weight and is heat stable indicates that it is unrelated to the high molecular weight, heat-labile factor required for the maintenance of rat 
sperm motility (Morita \& Chang, 1970). For the same reason it is apparently unrelated to the commercially used colloidal sperm diluents.

Recently, Crabo etal. (1967) and Einarsson (1971) have reinvestigated the composition of CEF compared to that of seminal plasma and have confirmed the previously reported (Mann, 1964) significant differences in ionic and osmotic factors. However, none of these differences appears relevant to sperm survival, including the unusual glycerylphosphorylcholine levels.

The isolation and identification of the epididymal fluid factor would appear to have considerable practical and theoretical significance. The effect upon spermatozoa of higher concentrations of epididymal fluid than used here would be of great interest. J. M. Cummins (personal communication) has stored quiescent epididymal spermatozoa in undiluted epididymal fluid and has found them to become highly motile upon dilution after 3 days at $37^{\circ} \mathrm{C}$. Until the epididymal fluid factor is identified, it must be assumed that hamster sperm samples that survive well always contain undefined external survival factors.

Regarding the effects of serum and caffeine upon sperm motility, it is clear that both elevate sperm cAMP levels but by different means. Caffeine inhibits the degradation of this compound (Garbers, Lust, First \& Lardy, 1971) while serum stimulates its synthesis by activating hamster sperm adenyl cyclase (Morton \& Albagli, 1973). How the level of sperm cAMP can control the rate of motility has become clearer after the recent discovery of large amounts of cAMP-dependent protein kinase in the cytosol of bull spermatozoa (Garbers, First \& Lardy, 1973; Hoskins, Casillas \& Stephens, 1972). It is also known that cAMP-dependent protein kinase of muscle phosphorylates troponin, a protein believed to control contractility (Bailey \& Villar-Palasi, 1971).

A comparison of the various data presented here suggests that, unlike caffeine and serum, epididymal fluid preserves sperm survival by a means other than the elevation of cAMP. We are at present measuring the effect of epididymal fluid upon sperm cAMP levels. The basis for the difference between the effect of caffeine on bull and hamster sperm survival is unclear. We have increased the caffeine concentration to the $10 \mathrm{~mm}$ used by Garbers, First, Sullivan \& Lardy (1971) but find no significant change in the percentage of hamster spermatozoa surviving at $4 \mathrm{hr}$.

It is interesting that, although caffeine and serum dialysate have similar effects upon the rate of sperm motility, only serum dialysate capacitated the spermatozoa in the presence of albumin. In view of the small numbers of ova examined, these results must be considered very preliminary, but they appear to suggest that serum dialysate may be required in sperm capacitation for reasons beyond the activation of sperm motility.

\section{ACKNOWLEDGMENTS}

This research was supported in part by a grant (HD-04738) from the National Institutes of Health. Technical assistance was supplied by Mrs L. Adams.

T. S. K. Chang was supported by a Ford Foundation Predoctoral Fellowship (660-0202A) from the Department of Anatomy and Reproductive Biology, University of Hawaii. 


\section{REFERENCES}

Bailey, C. \& Villar-Palasi, G. (1971) Cyclic AMP-dependent phosphorylation of troponin. Fedn Proc. Fedn Am. Socs exp. Biol. 30, 552.

Grabo, B., Gustafsson, B., Bane, A., Meschaks, P. \& Ringmar, J. E. (1967) The concentration of sodium, potassium, calcium, inorganic phosphate, protein and glycerylphosphorylcholine in the epididymal plasma of bull calves. J. Reprod. Fert. 13, 589 .

Einarsson, S. (1971) Studies on the composition of epididymal content and semen in the boar. Acta vet. scand. Suppl. 36, 3.

Garbers, D. L., First, N. L. \& Lardy, H. A. (1973) The properties of adenosine 3', 5'-monophosphatedependent protein kinases isolated from bovine epididymal spermatozoa. 7 . biol. Chem. 248, 875.

Garbers, D. L., First, N. L., Sullivan, J. J. \& Lardy, H. A. (1971) Stimulation and maintenance of ejaculated bovine spermatozoan respiration and motility by caffeine. Biol. Reprod. 5, 336.

Garbers, D. L., Lust, W. D., First, N. L. \& Lardy, H. A. (1971) The effects of phosphodiesterase inhibitors and cyclic nucleotides upon sperm respiration and motility. Biochemistry, 10, 1825.

Hoskins, D. D., Casillas, E. R. \& Stephens, D. T. (1972) Cyclic AMP-dependent protein kinases of bovine epididymal spermatozoa. Biochem. biophys. Res. Commun. 48, 1331.

Koelliker, A. (1856) Z. wiss. Zool. 7, 201, as cited in Mann, T. (1964).

ManN, T. (1964) The biochemistry of semen and of the male reproductive tract, p. 343. Methuen, London.

Morita, Z. \& Chang, M. C. (1970) Motility and aerobic metabolism of spermatozoa in laboratory animals with special reference to the effects of cold shock and the importance of calcium for the motility of hamster spermatozoa. Biol. Reprod. 3, 169.

Morton, B. \& Albagli, L. (1973) Modification of hamster sperm adenyl cyclase by capacitation in vitro. Biochem. biophys. Res. Commun. 50, 697.

Morton, B., Rogers, B. J. \& Ghang, T. S. K. (1973) Gapacitation of large numbers of hamster sperm in vitro. Biol. Reprod. (In press).

Phillips, P. H. \& LARdy, H. A. (1940) A yolk-buffer pabulum for the preservation of bull semen. 7. Dairy Sci. 23, 399.

YanAGiMAGHi, R. (1970) The movement of golden hamster spermatozoa before and after capacitation. 7. Reprod. Fert. 23, 193. 